\title{
A relação entre a leitura e a capacidade noética de autodistanciamento
}

The relationship of reading with the noetic capacity of self-distancing

https://doi.org/10.34112/2317-0972a2021v39n83p159-165

Suzaneide Oliveira Medrado ${ }^{1}$

HERNÁN EdUARDo LANOSA ${ }^{2}$

RESUMO: O presente ensaio trata da leitura, pensada a partir de uma perspectiva existencialista, visto que se trata de uma atividade complexa da linguagem, mediada por meio da interação entre o leitor e o texto, que envolve a reflexão. Dessa maneira, a leitura pode contribuir para o desenvolvimento de capacidades mais elevadas, noéticas, como o autodistanciamento, que se refere à reflexão sobre o próprio ser e sobre as situações para fazer escolhas mais coerentes com os valores e crenças. No ato de ler o leitor reflete à luz de suas experiências de vida e de leitura, na vida, também o ser humano, por meio da capacidade noética de autodistanciamento, reflete sobre os acontecimentos a partir de suas experiências, assim, é possível pensar numa relação estreita entre a leitura e o autodistanciamento. PALAVRAS-CHAVE: Leitura; capacidade noética de autodistanciamento; reflexão.

ABSTRACT: This essay deals with reading, thought from an existentialist perspective, since it is a complex activity of language, mediated through the interaction between the reader and the text, which involves the reflection. In this way, reading can contribute to the development of higher, noetic capacities, such as self-distancing, which refers to the reflection on one's being and on situations to make choices more consistent with values, beliefs, since, in the

1. Secretaria Estadual de Educação da Bahia- SEC-BA.

2. Fundación Argentina de Logoterapia Viktor Frankl. 
act of reading the reader reflects in the light of his life and reading experiences, in life, the human being, through the noetic capacity for self-distancing, reflects on the events from his experiences, thus, it is possible to think of a relationship between reading and self-distancing. KEY WORDS: Reading; noetic capacity for self-distancing; reflection.

Pode-se pensar a leitura como uma atividade complexa da linguagem que contribui para desenvolver diferentes capacidades, conhecimentos e experiências que propiciam uma formação holística ao leitor. Pensar sobre a complexidade da leitura com relação à formação global do indivíduo pode direcionar para a promoção de capacidades mais elevadas, que incluem reflexão e autoconsciência.

Ademais, é possível compreender a leitura como uma ponte que interliga o ser humano a si mesmo e a sua realidade. No ato de ler, as experiências do leitor dialogam com as ideias contidas no texto, estabelecendo-se uma relação que culmina no sentido, na transformação do texto e do próprio ser.

A leitura está relacionada ainda a um processo de aprendizagem perene e em permanente construção que se alia à identidade humana, sempre imperfeita. Desse modo, essa atividade precisa ser pensada como um projeto de vida almejado por todo ser humano, uma vez que pode contribuir para a promoção de uma educação integradora (SARDINHA, 2007).

Nessa perspectiva, a leitura se concretiza a partir da atitude responsiva do leitor, dos sentidos que este constrói por meio de um processo de pensamento e reflexão, à luz dos conhecimentos prévios e experiências. Esse processo contribui para o percurso formativo do leitor e para que o texto realize sua função comunicativa, dialógica. Assim, a leitura "se faz por relação metafórica, com o sentido aproximado de encontrar significação pessoal em algo com base nas suas observações e vivências" (BRITTO, 2012, p. 23).

Dessa maneira, a leitura pode ser pensada a partir de uma perspectiva existencialista, uma vez que se efetiva por meio da reflexão; assim, exige um distanciamento para que seja possível a relação entre as ideias dos textos e os conhecimentos e ideias do leitor, que culminarão na atribuição de sentido.

De acordo com Buber (1979), pensamento e reflexão assinaram um pacto indestrutível com a situação da existência. Do mesmo modo, a leitura inclui esses dois elementos, uma vez que é mediada por processos de pensamento (ALLIENDE; CONDEMARÍN, 2005) e pela interação, na qual o leitor reflete sobre o texto à luz das suas experiências de vida e de leitura. 
As experiências leitoras são base para a atribuição de sentido a novos textos, uma vez que se valem dos sentidos construídos, de ideias e vocabulários subsidiados pelas diferentes leituras; assim se amplia o arcabouço de conhecimentos, bem como as competências e habilidades que permitem ao leitor progredir cada vez mais no conhecimento de mundo e de si mesmo.

Na leitura, emerge a biblioteca vivida do leitor, ou seja, as experiências oriundas das leituras anteriores e da cultura. Essa biblioteca se refere a um sistema de valores que vem à tona no ato de ler (GOULEMOT, 2001). A interação do leitor com o texto envolve os valores e as crenças que são cruciais para o processo de construção de sentidos. Pode-se dizer que, pela subjetividade implicada no processo de atribuir sentido à leitura, o leitor constrói um texto paralelo, imbuído de suas experiências, valores e crenças, mas intimamente relacionado com o texto publicado (GOODMAN, 1985).

No ato de ler, há um distanciamento do leitor que é importante para que ele pense sobre as ideias sem confundir-se com o que lê. De acordo com Martins (2006, p. 66), "ao mesmo tempo em que o leitor abandona a si mesmo na busca da realidade do texto, sua percepção implica uma volta à sua experiência pessoal e uma visão da própria história do texto", num processo reflexivo e interativo.

Esse distanciamento do leitor favorece o desenvolvimento de capacidades noéticas, em especial, o autodistanciamento. $\mathrm{O}$ noético se refere às atividades do intelecto. Depreende-se da filosofia de Artistóteles, que o intelecto é a melhor parte da alma. Ainda a partir do significado aristótelico, o noético se refere à atividade contemplativa que leva à reflexão. De acordo com Arendt (2009, p. 27), a contemplação "é o único modo de vida verdadeiramente livre".

A dimensão noética é, então, a dimensão espiritual, no sentido da consciência humana, em perspectiva antropológica, não teológica; assim, é a capacidade que o homem tem de pensar sobre si e sobre todas as coisas. Essa dimensão é aquela onde se localizam os fenômenos especificamente humanos (FRANKL, 2011). Para Scheler (1979), o espírito propicia ao ser humano a capacidade de transcender toda cadeia determinante, todo meio de condicionamento, possibilitando ao homem espiritual tornar tudo alvo de ação para si, inclusive sua própria natureza anímica (Scheler, 1979).

Sobre as características do espírito, Frankl (2011) considera o pressuposto dialógico como algo fundamental, no qual todas as coisas só existem a partir do compartilhamento, uma vez que o princípio da existência é a relação. Assim, o espírito se manifesta por meio da capacidade de pensar, de se relacionar, o que torna possível a consciência da existência de si mesmo e do outro. 
Ainda sobre a dimensão espiritual, noética, Frankl (2011, p. 28) esclarece:

No momento em que o homem reflete sobre si mesmo - ou se for necessário, rejeita a si mesmo; quando ele faz a si próprio de objeto - ou aponta objeções a si mesmo; no momento em que manifesta sua consciência de si, ou quando exibe seu ser consciente, então o ser humano atravessa a dimensão noológica.

A capacidade noética de autodistanciamento é a "capacidade de distanciar-se não apenas de uma situação, mas de si mesmo" (FRANKL, 2011, p. 27), e, ainda, "a capacidade de monitorar e controlar os próprios processos emotivos e cognitivos” (MARTINEZ, 2012, p. 5), para pensar sem se confundir com as coisas que ocorrem, e escolher, por meio da reflexão, as melhores ações para responder aos diversos acontecimentos.

$\mathrm{O}$ autodistanciamento é muito importante para a liberdade humana. Por meio dessa capacidade, o ser humano pode dar respostas mais autônomas e não simplesmente reproduzir as ações da massa (MARTINEZ, 2012). Assim, ele está relacionado aos altos níveis de consciência, que permitem ao homem ir além dos próprios condicionamentos para escolher as melhores respostas às situações diversas e viver com mais liberdade e qualidade em suas relações e em sua vida de maneira geral. Ainda por meio da capacidade noética de autodistanciamento, é possível ao ser humano responder às situações de uma maneira mais autônoma, responsável, sem demonstrar comportamentos impulsivos e impensados que por vezes vão de encontro à liberdade e essência do próprio ser.

Assim como na vida, no ato de ler, o homem toma distância de si, de suas ideias e condicionamentos, para refletir e fazer questionamentos sobre as ideias dos textos. Dessa maneira, "o distanciamento crítico, característico da leitura racional, induz à predisposição para o questionamento” (MARTINS, 2006, p. 70).

No processo de leitura, o leitor eficiente faz questionamentos, pensa sobre si mesmo, demonstrando autoconsciência. A capacidade noética de autodistanciamento está relacionada com a consciência que o homem tem sobre sua condição, sobre si mesmo. Frankl (2011), ao falar sobre as capacidades espirituais, noéticas, afirma que elas ampliam nosso nível de consciência e possibilitam o desenvolvimento e a superação, tanto em relação à individualidade, quanto em relação à espécie.

Semelhante ao que ocorre na vida do ser humano, na leitura, a consciência do leitor é muito importante para que a atitude responsiva aconteça (BAKHTIN, 
1986). A consciência de si mesmo, do contexto que está próximo e do que de fato é relevante para si, é o que oferece suporte ao leitor para o processo reflexivo, que inclui fazer questionamentos, já que "ler significa ser questionado pelo mundo e por si mesmo" (FOUCAMBERT, 1994, p. 5), duvidar das informações, concordar ou discordar de ideias, adicionar informações e, por fim, atribuir sentido à leitura.

Tornar-se consciente de si, fazendo reflexão da própria existência, é o que traz à tona o espírito. O homem não só pode elevar o "meio" à dimensão do mundo e fazer das "resistências" "objetos", mas também converter em objetiva sua própria constituição fisiológica e cada uma de suas vivências psíquicas (SCHELER, 1979).

A leitura contribui para propiciar uma relação mais profunda e significativa entre o leitor e o texto, uma vez que se efetiva por meio da reflexão e do diálogo provocativo e questionador que conduz à reflexão do próprio ser. A reflexão que ocorre no ato de ler pode ser pensada a partir da metáfora do espelho; palavras e ideias lidas são compreendidas e ganham sentido por meio da subjetividade do leitor. "Ler é reconhecer o mundo através de espelhos" (LEFFA, 1996, p. 10); estes apresentam imagens em que são retratadas partes da realidade; dessa maneira, a leitura se efetiva a partir da visão e do conhecimento prévio de mundo do leitor.

Ainda sobre a reflexão presente no ato de ler, Cassirer (1967) discute a ideia do pensamento reflexivo, que ocorre por meio da segregação e do isolamento de elementos e fenômenos que permitem fixar a concentração e o pensamento para uma melhor reflexão sobre esses mesmos elementos e fenômenos. "O homem mostra reflexão quando o poder de sua alma atua tão livremente, que de todo oceano de sensações que fluem através dos sentidos, pode segregar" (CASSIRER, 1967, p. 39). Dessa maneira, diante dos diversos estímulos, o ser humano pode selecionar algum aspecto ou algo que seja do seu interesse ou que tenha relação com seus valores, crenças e sentido e refletir sobre ele.

Assim, também no ato de ler, o leitor pode segregar, ou seja, destacar ideias e demorar-se naquelas que sejam mais relevantes para atender seus objetivos de leitura, ou que sejam mais significativas para si. Isso é possível porque há um distanciamento necessário para dialogar e refletir sobre as ideias dos textos e a elas atribuir sentido.

$\mathrm{Na}$ construção e identificação da ideia principal do texto, o leitor segrega ideias para pensar sobre elas; "as ideias principais são mais próximas da leitura autônoma e têm uma importante repercussão na memória” (SOLÉ, 1988, p. 138). Nesse processo, o leitor seleciona ideias para fazer uma melhor reflexão sobre o que considera mais importante no texto. 
A partir do que tem relevância para si e para atender os objetivos de leitura, o leitor constrói um novo texto e novos sentidos além dos que são esperados pelo autor no ato da escrita. Isso acontece porque a leitura se concretiza em uma relação dialógica e reflexiva, possível por meio do distanciamento do leitor no ato de ler que suscita sentidos advindos das ideias dos textos e de sua própria concepção de mundo, adquirida com base em suas experiências socioculturais.

Por meio da capacidade noética de autodistanciamento, o homem pode pensar melhor sobre si mesmo e sobre as situações vividas para fazer escolhas mais autônomas, uma vez que, quando o ser humano pensa sobre si e sobre o papel que tem em sua própria vida e na sociedade, tende a ser mais coerente consigo mesmo em suas ações. Assim, é possível pensar a existência de uma relação estreita entre a leitura e a capacidade noética de autodistanciamento, uma vez que os dois ocorrem por meio da reflexão, intermediada pelas experiências.

Na vida do ser humano, toda escolha leva em conta as experiências, que são essenciais para a aprendizagem. Assim, também a leitura se efetiva pela interação entre as experiências do leitor e as ideias contidas nos textos, num processo de reflexão que inclui os objetivos de leitura e os valores e crenças do leitor, para que a atribuição de sentido ocorra de maneira mais coerente.

Dessa maneira, tanto a vida do ser humano quanto a leitura se fundamentam em capacidades importantes, como o autodistanciamento, que conduz à reflexão e à autoconsciência para atribuição de sentido na leitura e para escolhas mais autônomas na vida. Sendo a leitura uma atividade humana, é relevante considerar os conceitos e fundamentos existencialistas como subsídios para compreender os processos de leitura que de fato tornam o ato de ler pleno de sentido, satisfação e realização e contribuem para a formação humana.

\section{REFERÊNCIAS}

ALLIENDE, F.; CONDEMARÍN, M. A leitura: Teoria, avaliação e desenvolvimento. Porto Alegre: Artmed, 2005.

ARENDT, H. La vida del espíritu: el pensar, la voluntad y el juicio en la Filosofía y en la política. Madrid: Centro de Estudios Constitucionales, 1984.

BRITTO, L. P. L. Leitura: Acepções, sentido e valor. Nuances: estudos sobre Educação, Presidente Prudente/SP, v. 21, n. 22, p. 18-31, 2012.

BUBER, M. Eu e tu. São Paulo: Cortez Moraes, 1979. 
CASSIRER, E. Antropología Filosófica: Introducción a una filosofía de la cultura. Mexico: Fondo de cultura económica, 1967.

FOUCAMBERT, J. A leitura em questão. Porto Alegre: Artes Médicas, 1994.

FRANKL, V. A Vontade de Sentido. São Paulo: Paulus, 2011.

GOODMAN. K. The reading process. In: Carrel, P. L; DEVINE, J.; ESKEY, D. E. Interactive approaches to second language reading. Cambridge: Cambridge University Press, 1988. p. 11-25.

LEFFA, V. J. Aspectos de leitura: uma perspectiva psicolinguística. Porto Alegre/ RS: Sagra-DC Luzzatto, 1996.

MARTINS, M. H. O que é leitura. São Paulo/ SP: Brasiliense, 2010.

MARTINEZ, E. La logoterapia de Viktor Frankl como psicoterapia contemporánea. Revista Peruana de Logoterapia Clínica y enfoques afines, Lima/PE, n. o1, p. 1-17, 2012.

SARDINHA, M. G. Literacia em leitura: Identidade e construção da cidadania. Recuperado em o1 de outubro de 2016, de http://bad.pt/publicacoes/index.php/congressosbad/article/view/510/pdf, 2007.

SCHELER, M. El puesto del hombre en el cosmos. Buenos Aires: Betiles, 1979.

SILVA, E. T. $O$ ato de ler: fundamentos psicológicos para uma nova pedagogia da leitura. São Paulo: Cortez, 2011.

SOLÉ, I. Estratégias de leitura. Porto Alegre: Artmed, 2008.

\section{SOBRE OS AUTORES}

Suzaneide Oliveira Medrado é Pós-doutora pela Universidad de Flores - UFLO (Argentina), Doutora em Psicologia Social pela Universidad Argentina John F. Kennedy-UK, Mestre em Educação pela Universidade Lusófona (Portugal). Graduada em Letras Vernáculas pela UNEB- Universidade Estadual da Bahia. Professora na rede de ensino da Secretaria Estadual de Educação da Bahia- SECBA e na rede de ensino de Queimadas/BA. Orientadora de trabalhos acadêmicos. E-mail: suzymedrado@gmail.com.

ORCID: https://orcid.org/oooo-0003-3324-5023.

Hernán Eduardo Lanosa é doutor em Psicologia com menção Cognitivoexistencial pela Universidad de Flores - UFLO (Argentina). Membro do Comité Administrativo e docente de pós-graduação da Fundación Argentina de Logoterapia. Diretor e fundador da Logocoaching Argentina.

E-mail: doctor.hlanosa@gmail.com.

ORCID: https://orcid.org/oooo-ooo2-8024-9046.

Texto aprovado em 16/11/2021. 